\title{
The maternal sex determination gene daughterless has zygotic activity necessary for the formation of peripheral neurons in Drosophila
}

\author{
Michael Caudy, ${ }^{1}$ Ellsworth H. Grell, ${ }^{1}$ Christine Dambly-Chaudière, ${ }^{2}$ Alain Ghysen, ${ }^{2}$ Lily Yeh Jan, ${ }^{1}$ \\ and Yuh Nung Jan ${ }^{1}$ \\ ${ }^{1}$ Howard Hughes Medical Institute and Departments of Physiology and Biochemistry, University of California, San Francisco, \\ California 94143 USA; $^{2}$ Laboratoire de Genetique, Universite Libre de Bruxelles, 1640 Rhode-St-Genese, Belgium
}

\begin{abstract}
The daughterless (da) gene is known to have separate maternal and zygotic functions: Maternally supplied daughterless activity is required for proper sex determination and dosage compensation in female embryos, whereas loss of zygotically supplied $\mathrm{da}^{+}$activity causes embryonic lethality in both male and female embryos. We have found that the zygotic $\mathrm{da}^{+}$activity is necessary for neural development: The use of neuron-specific antibodies and $\beta$-galactosidase-marked $X$ chromosomes has revealed that in both male and female embryos deletions or strong mutations of the $d a$ gene remove all peripheral neurons and associated sensory structures without disrupting the epithelium from which they derive. Partial $\mathrm{da}^{+}$function causes partial removal of peripheral neurons. Our results indicate that $\mathrm{da}^{+}$is required for the formation of peripheral neurons and their associated sensory structures.
\end{abstract}

[Key Words: Neurogenesis; sex determination genes; peripheral nervous system; development; Drosophila]

Received January 27, 1988; revised version accepted April 15, 1988.

Sensory organs of insects arise in a precise spatio-temporal pattern within the epidermal primordium that forms the body wall. These sensory organs include sensory neurons that are located peripherally and any support cells that form associated sensory structures. Previous studies suggest that at least in some cases, the neuron(s) and support cells of a sensory organ arise from the same precursor (Wigglesworth 1953; Lawrence 1966; Bate 1978).

The mechanisms underlying sensory organ pattern formation are unknown but can be studied genetically and biochemically if mutations can be found that perturb the pattern. In Drosophila, two types of mutations have been found that alter the pattern of peripheral sensory neurons. Mutations that reduce the function of the neurogenic loci (for review, see Campos-Ortega 1985) increase the number of neurons in the central nervous system, as well as in the periphery (Hartenstein and Campos-Ortega 1986). In contrast, loss or reduction of function of the achaete-scute complex (AS-C) causes removal of specific subsets of sensory neurons and their associated sensory structures; deleting the entire AS-C locus eliminates all sensory neurons, except for one specific type, the chordotonal neurons (Dambly-Chaudiere and Ghysen 1987). In our screen for mutations that alter the pattern of sensory neurons (Jan et al. 1987), we have found that the deletion of a gene on the second chromosome causes elimination of all sensory neurons and their associated sensory structures. We show here that this gene is daughterless (da).

The first spontaneous mutation $d a, d a^{1}$ (Bell 1954) is a hypomorph, with reduced, but not zero, activity (Manage and Sandler 1973). Under certain temperature regimes, mothers homozygous for $d a^{1}$ produce normal male progeny but fewer or no female offspring (Sandler 1972; Cline 1976). The da gene appears to have multiple functions. (1) During embryogenesis, maternal $\mathrm{da}^{+} \mathrm{ac}^{-}$ tivity is necessary for normal activation of the sex determination gene, Sex lethal (Sxl), which elicits proper differentiation of female somatic tissues, as well as proper dosage compensation in female embryos: Lack of maternal $\mathrm{da}^{+}$activity causes incorrect dosage compensation and lethality in female embryos (Cline 1978, 1980, 1983, 1984; Lucchesi and Skripsky 1981; Gergen 1987). (2) In adult females, lack of $d a^{+}$activity results in nonfertile eggs of both sexes (Cline 1976; Cronmiller and Cline 1987). (3) In addition to these strictly maternal effects, both male and female homozygous $d a^{1}$ embryos from heterozygous parents also show a temperature-dependent reduction of viability (Cline 1976; Cronmiller and Cline 1986), suggesting that the $d a$ gene has additional zygotic function. This is supported by the recent 
finding that strong, probably null mutations of $d a\left(d a^{2}\right.$ and $d a^{3}$ ) are embryonic lethal (Cronmiller and Cline 1987).

The $\mathrm{da}^{+}$requirement for sex determination is strictly maternal (Cline 1976, 1980), whereas that for neural development is primarily zygotic (see below). This allows the two phenotypes to be separated experimentally. In this paper we analyze the embryonic phenotype and present genetic evidence indicating that the same gene is responsible for both sex determination and the formation of sensory organs.

\section{Results \\ Zygotic $\mathrm{da}^{+}$gene activity is required for the formation of sensory organs}

In our screen for mutations affecting the embryonic peripheral nervous system (PNS; Jan et al. 1987), we found that one deletion, $D f(2 L) / 27$, eliminates all peripheral neurons and associated sensory structures. This is similar to the phenotype of an ethylmethane sulfonate (EMS)-induced mutation, 1(2)IIB31, isolated by Nüsslein-Volhard et al. (1984). Homozygous 1(2)IIB31 embryos show no movement late in embryogenesis (C. Nüsslein-Volhard, pers. comm.) and have reduced central nervous system (CNS; Campos-Ortega, quoted in Nüsslein-Volhard et al. 1984). In addition to the CNS defect, we have found that these embryos also lack all peripheral neurons (Fig. 1) and have no external sensory structures. Subsequent genetic studies suggested that the similar phenotypes seen in $D f(2 L) / 27$ and $1(2) I I B 31$ embryos are due to lesions of the same gene: Genetic mapping of 1(2)IIB31 showed that the lethal mutation associated with the nervous system defects maps between fuzzy (2-33) and black (2-48.5) on the left arm of the second chromosome, the same region that contains $D f(2 L) / 27$. Furthermore, 1(2)IIB31/Df(2L)I27 embryos are lethal and show the same PNS and CNS defects as either homozygote. Therefore, 1(2)IIB31 probably inactivates one of the genes deleted by $D f(2 L) / 27$.

In testing complementation between 1(2)IIB31 and genes known to be deleted by $D f(2 L) / 27$ (Sandler 1977), we found that 1(2)IIB31 fails to complement da:1(2)IIB31/da embryos die (independently observed by J. Tomkiel, pers. comm.), as do $D f(2 L) / 27 / d a^{1} \mathrm{em}$ bryos (Mange and Sandler 1973). The mutation 1(2)IIB31 also fails to complement the lethality of two strong $d a$ mutations, $d a^{2}$ and $d a^{3}$. Furthermore, Cronmiller and Cline have shown that like $d a^{2}$ and $d a^{3}, 1$ (2)IIB31 affects sex determination: Females containing two copies of $d a^{1}$ on one chromosome [Dp $\left(d a^{1}\right) 119$ ] (Cronmiller and Cline 1986) and 1(2)IIB31 on the other produce no daughters at $25^{\circ} \mathrm{C}$. Moreover, 1(2)IIB31 interacts with other sex-determination mutations in the same way as do previously identified da mutations: 1(2)IIB31 interacts with Sxl and sisterless- $a$ (sis-a) mutations so that $>98 \%$ of female transheterozygotes of $S \times 1$ and sis- $a$ from mothers heterozygous for 1(2)IIB31 die (C. Cronmiller and T. Cline, pers. comm.; for discussion of these tests for sex deter- mination function, see also Cronmiller and Cline 1987). Thus, 1(2)IIB31 fails to complement the lethality of $d a$ mutations and behaves as a null allele of $d a$, with respect to the maternal function in sex determination.

To determine whether $d a$ mutations, such as the strong alleles $d a^{2}$ and $d a^{3}$ and the hypomorphic allele $d a^{1}$, also affect the nervous system, we stained $d a$ mutant embryos with neuron-specific antibodies. The parents of these mutant embryos carry the wild-type $d a$ gene on one chromosome so that sufficient maternal $d a^{+}$activity is present in the embryos for proper sex determination and dosage compensation (Cline 1976; Cronmiller and Cline 1987). Embryos of the genotype $d a^{2} / d a^{2}, d a^{3} / d a^{3}, d a^{2} / 1(2) I I B 31$, or $d a^{3} / 1(2) I I B 31$, show a phenotype similar to that of homozygotes of 1(2)IIB31 or $D f(2 L)$ I27: All sensory neurons are missing, and the CNS is abnormal (Table 1). Although $d a^{1} / d a^{1}$ embryos show no detectable abnormalities in their PNS or CNS, $d a^{1 / 1}$ (2)IIB31 embryos show a reduction in sensory neurons (Fig. 2; Table 2). Similar reductions in sensory neurons are seen in $d a^{1} / D f(2 L) / 27$ embryos (data not shown).

Taken together, these results show that the CNS and PNS defects of 1(2)IIB31 are due to a mutation of the $d a$ gene, hereafter designated $d a^{I I B 31}$. Each of the $d a$ mutations identified previously also acts zygotically and causes a reduction or total removal of sensory neurons in embryos.

\section{The phenotype of homozygous da mutant embryos}

In crosses between flies heterozygous for a strong $d a$ mutation, one quarter of the progeny has no peripheral (sensory) neurons (Table 1). When X-linked markers are used to determine the sex of embryos (as described later), both male and female mutant embryos lack peripheral neurons (data not shown). The nonneural tissues, on the other hand, appear to differentiate normally in mutant embryos throughout the 8- to 11-hr period in which the PNS would normally arise (embryogenesis takes $22 \mathrm{hr}$ at $25^{\circ} \mathrm{Cl}$

Gut The gut is formed by the invagination of the ectodermally derived foregut and hindgut and by endodermal cells that spread over the yolk mass and fuse dorsally and ventrally to form the midgut (Campos-Ortega and Hartenstein 1985). In wild-type embryos, this fusion of the midgut and its connection with the foregut and hindgut occurs $\sim 12 \mathrm{hr}$ after fertilization. This characteristic morphology is found in $>95 \%$ of the mutant $d a^{\amalg 331}$ embryos (e.g., cf. Fig. lc,d).

Muscles Wild-type embryos begin to label with the muscle-specific monoclonal antibody 6D5 at about $12 \mathrm{hr}$ after fertilization, and the muscle pattern is essentially complete by $14-15 \mathrm{hr}$ (Fig. 3a). In $d a^{I I B 31}$ mutant embryos (identified by clearly visible defects in their CNS), the muscles always begin to label with the 6D5 antibody at about $12 \mathrm{hr}$ but show variable defects (Fig. 3b). In some cases, the muscles arise in essentially their normal positions and numbers, although a few muscle fibers ap- 
2

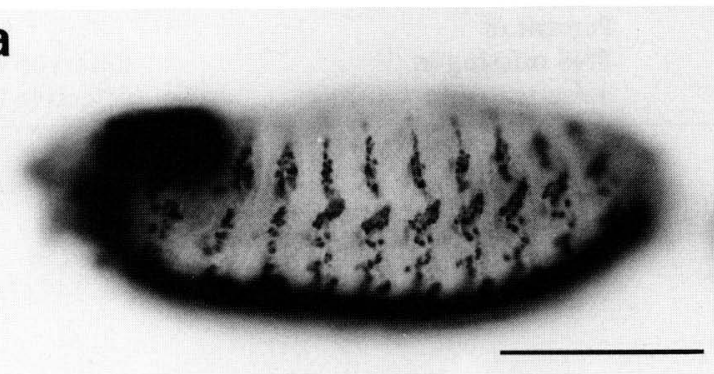

C
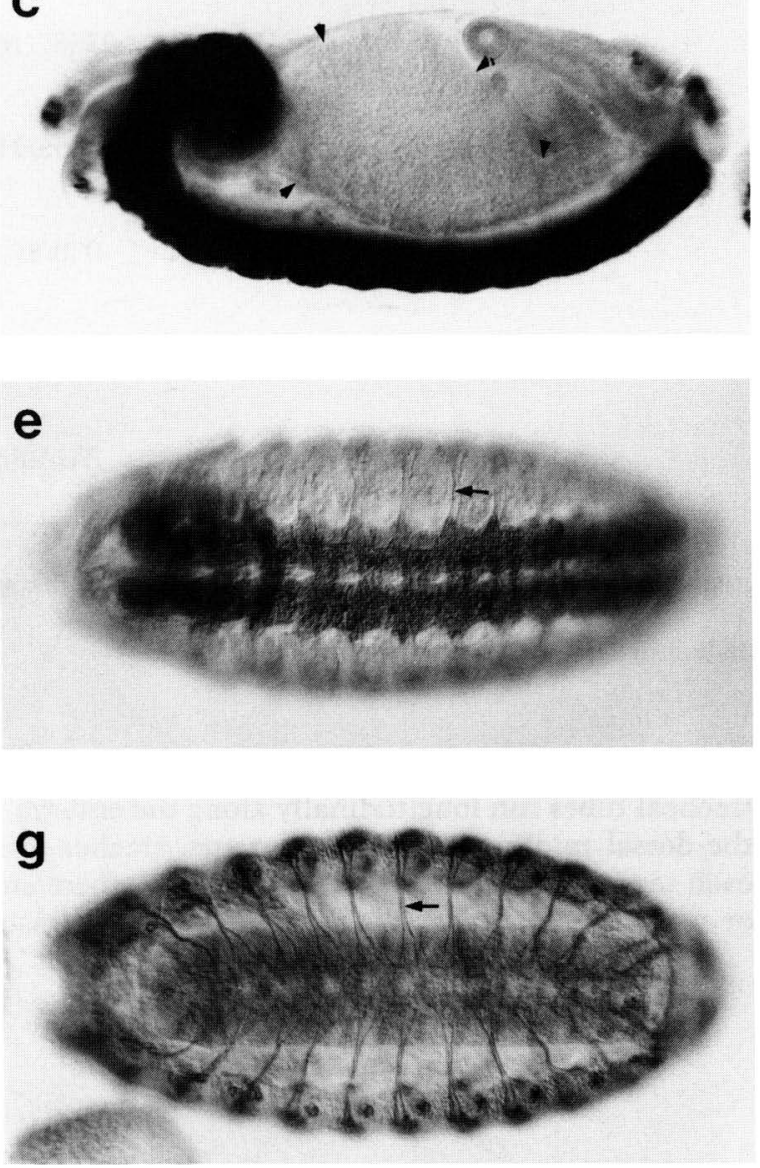
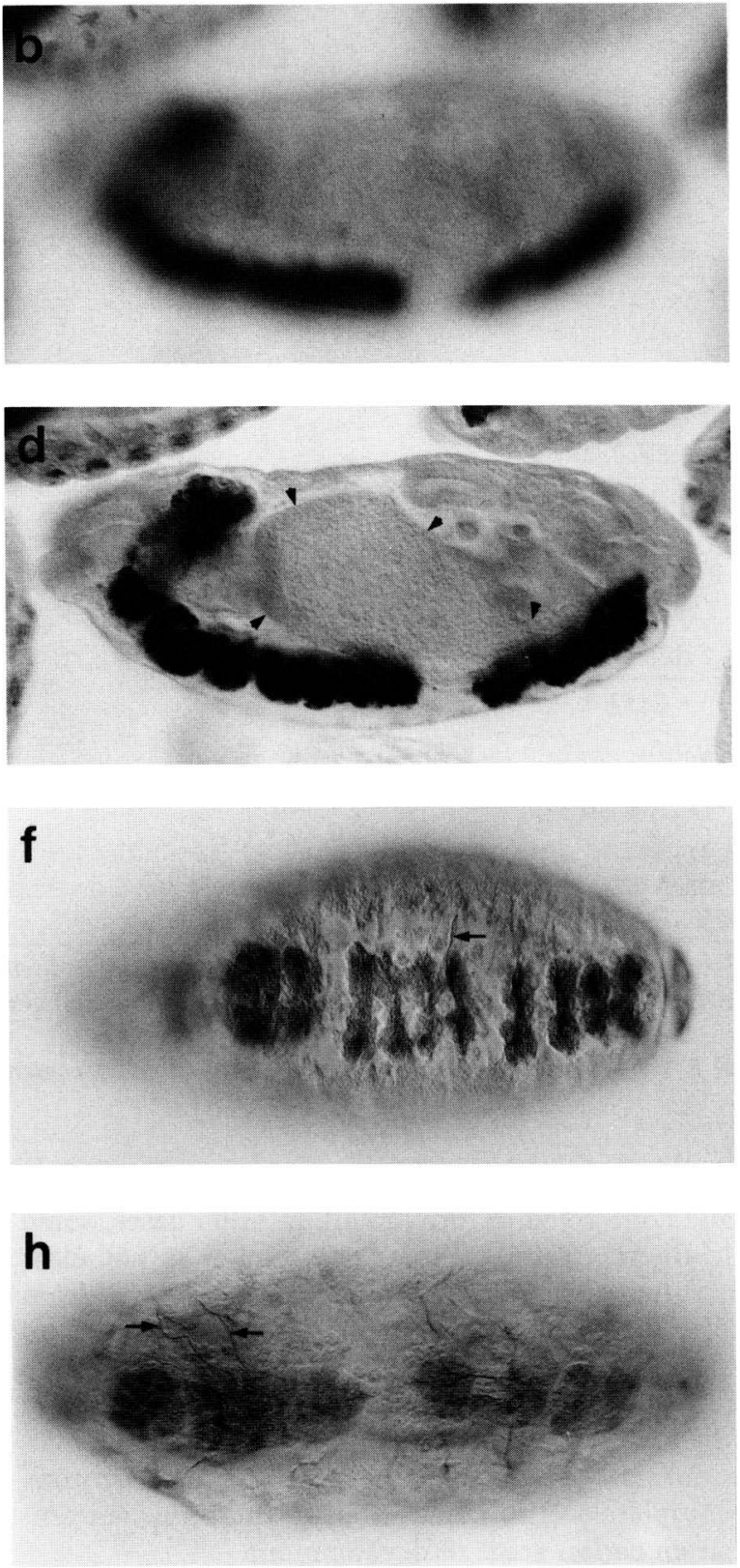

Figure 1. Nervous system defects in $d a^{I I B 31}$ homozygous embryos. (a) Wild-type embryo stained with the neuron-specific monoclonal antibody $44 \mathrm{C} 11$, which specifically labels neuronal nuclei. At this stage, the complete set of peripheral neurons has arisen and is repeated segmentally along the length of the embryo. Anterior is to the left in this and all other figures. Dorsal is up in $a-d$ and in all figures showing a lateral view of the embryo. Development can be staged by the degree of retraction and condensation of the CNS. The location of the posterior end of the CNS at the posterior end of the embryo indicates that this embryo is about 12 hr after fertilization. (b) A 12-hr mutant embryo, stained with $44 \mathrm{Cll}$. The focal plane is on the peripheral epithelium, as in $a$. No peripheral neurons are evident; the defective CNS is labeled but not in focus. $(c)$ The same wild-type embryo as in $a$ but with the focus on the CNS, which extends along the ventral (bottom) side of the embryo. The midgut has differentiated to form a single sack (arrowheads) encasing the yolk completely and tapering to connect with the hindgut at its posterior end. (d) The same dallB31 embryo as in $b$ but with the plane of focus on the CNS. The CNS is abnormal, with a prominent gap in the ventral nerve cord, as well as defects in the brain. Gut morphology (outlined by arrowheads) is normal. (e) Ventral view of a 10-hr wild-type embryo labeled with anti-HRP antibodies. The CNS extends continuously along the ventral side of the embryo. $|f|$ Ventral view of a $10-\mathrm{hr} d a^{I I B 31} \mathrm{mutant}$ embryo labeled with anti-HRP antibodies, showing segmental gaps in the CNS. Labeled processes extend from the CNS into the periphery. $(g)$ Ventral view of a 10-hr wild-type embryo stained with monoclonal antibody $21 \mathrm{~A} 4$, which labels neuronal cell bodies and processes. Segmental nerves (arrow) extend laterally from the CNS in each segment. ( $h$ ) Ventral view of a 10-hr daIIB31 mutant embryo labeled with $21 \mathrm{~A} 4$. Labeled processes (arrows) extend from remaining clumps of central neurons. Scale bar represents $100 \mu \mathrm{m}(a, b), 110 \mu \mathrm{m}$ $(c-f)$, and $120 \mu \mathrm{m}(g, h)$. 
Caudy et al.

Table 1. Complementation analysis and embryonic phenotype of 1(2)IIB31 and da alleles

\begin{tabular}{|c|c|c|c|}
\hline $\begin{array}{l}\text { Cross: } \\
(\text { female } \times \text { male })^{a}\end{array}$ & $\begin{array}{l}\text { Embryos with } \\
\text { defective PNS }(\%)\end{array}$ & $\begin{array}{l}\text { Percent of } \\
\text { PNS missing in } \\
\text { defective embryos }\end{array}$ & $\begin{array}{l}\text { Embryos with } \\
\text { defective CNS }(\%)\end{array}$ \\
\hline$\frac{1(2) \text { IIB31 }}{\mathrm{CyO}} \times \frac{1(2) I I B 31}{\mathrm{CyO}}$ & $27(34 / 124)$ & $100(34 / 34)$ & $27(34 / 124)$ \\
\hline$\frac{d a^{3}}{C y o} \times \frac{d a^{3}}{C y o}$ & $24(27 / 114)$ & $100(27 / 27)$ & $24(27 / 114)$ \\
\hline$\frac{d a^{2}}{C y o} \times \frac{d a^{2}}{\text { Cyo }}$ & $23(19 / 81)$ & $100(19 / 19)$ & $23(19 / 81)$ \\
\hline$\frac{d a^{3}}{C y O} \times \frac{1(2) I B B 31}{C y O}$ & $23(37 / 161)$ & $100(37 / 37)$ & $23(37 / 161)$ \\
\hline$\frac{d a^{2}}{C y O} \times \frac{1(2) I I B 31}{C y O}$ & $26(55 / 214)$ & $100(55 / 55)$ & $26(55 / 214)$ \\
\hline$\frac{d a^{1}}{C y O} \times \frac{1(2) I I B 31}{C y O}$ & $28(25 / 89)$ & $17^{b}$ & $0(0 / 89)$ \\
\hline$\frac{d a^{1}}{+} \times \frac{d a^{1}}{+}$ & $0(0 / 31)$ & $0(0 / 31)$ & $0\langle 0 / 31\rangle$ \\
\hline$\frac{1(2) I I B 31}{t} \times \frac{t}{+}$ & $0(0 / 26)$ & $0(0 / 26)$ & $8(2 / 26)^{c}$ \\
\hline
\end{tabular}

a In each cross, the genotype of the female is given first, followed by the male.

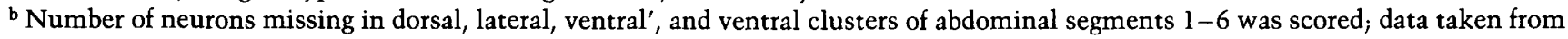
Table 2 .

c These $8 \%$ embryos showed CNS constrictions like those seen in female progeny of $d a^{1} / d a^{1}$ mothers (Fig. 5a).

pear to have broken away from one of their attachment sites and contracted to form a ball. In other cases, some muscle fibers are missing entirely, and it is not clear whether they arose normally and later broke away from both of their attachment sites, whether they failed to arise at all, or whether they eventually would have arisen had the embryos been fixed at a later time. In any case, the majority of muscles form and differentiate relatively normally, even though the peripheral neurons were completely eliminated in all of these mutant embryos at an earlier stage of development.

Figure 2. Partial PNS reduction of $d a^{1} / d a^{I I B 31}$ embryos. $|a| \mathrm{A}$ 13-hr wild-type embryo labeled with the $44 \mathrm{Cll}$ antibody. Distinct dorsal (d) and lateral (1) clusters of peripheral neurons are present in each segment. In the abdominal segments (Abd bracket) there are between 11 and 13 neurons in each dorsal cluster, and between 12 and 13 neurons in each lateral cluster. (b) A 44C11-labeled 13-hr embryo from the cross $d a^{1} / \mathrm{CyO} \mathrm{X}$ $\mathrm{da}^{I I B 31} / \mathrm{CyO}$ (CyO is a $\mathrm{da}^{+}$balancer chromosome). The number of peripheral neurons in each cluster is reduced, with as few as six neurons present in some abdominal dorsal clusters. The longitudinal spacing between these clusters is normal. About $25 \%$ of the embryos from this cross (but not in control crosses of flies carrying the $\mathrm{CyO}$ balancer chromosome) show reductions in the number of peripheral neurons; these are presumed to be of the genotype $d a^{1} / d a^{I I B 31}$. Scale bar represents $100 \mu \mathrm{m}$ $(a, b)$.
Trachea In wild-type 13- to 15 -hr embryos, prominent tracheal tubes run longitudinally along the embryo, near the dorsal midline. In $d a^{I I B 31}$ mutants, trachea arise in each segment, but generally $(90 \%$; Table 3$)$ there are one or more regions in which the trachea fail to fuse and
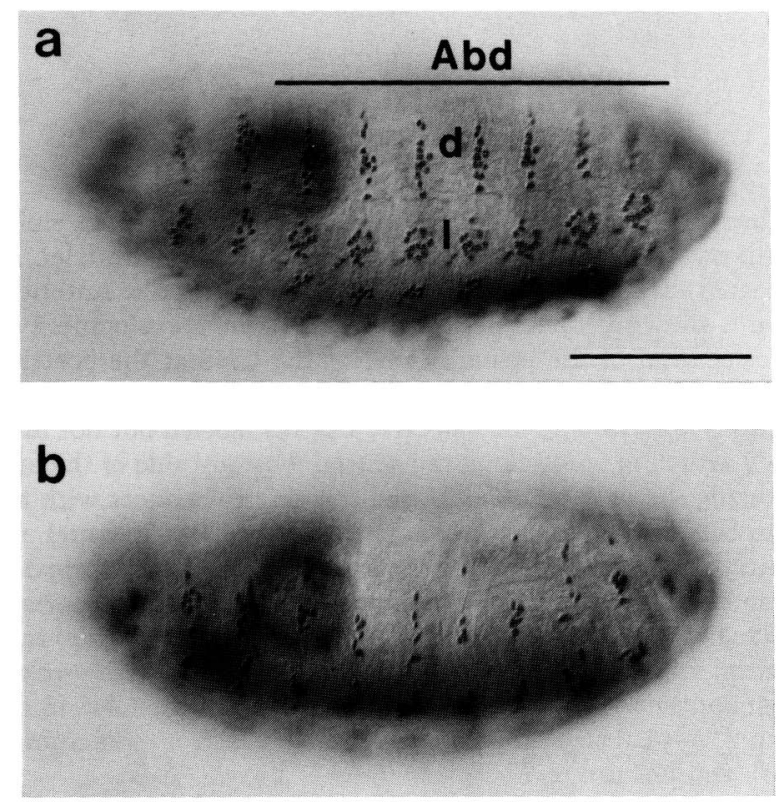
Table 2. Partial PNS defects in progeny of $\mathrm{da}^{1} /+\times 1 / 2 \mid \mathrm{IIB} 31 /+$

\begin{tabular}{lllll}
\hline $\begin{array}{l}\text { Cross: } \\
\text { (female } \times \text { male) }\end{array}$ & Dorsal cluster & Lateral cluster & Ventral' cluster & Ventral cluster \\
\hline+ & M: $12.5+/-0.6$ & M: $13.0+/-0.5$ & M: $8.0+/-0.2$ & M: $11.0+/-0.1$ \\
+ & R: $11-13$ & R: $12-13$ & R: $7-8$ & $\mathrm{R}: 10-11$ \\
& $\mathrm{n}=45$ & $\mathrm{n}=60$ & $\mathrm{n}=59$ & $\mathrm{n}=60$ \\
$\frac{d a^{1}}{+} \times \frac{1(2) I I B 31}{+}$ & $\mathrm{M}: 10.3+/-1.4$ & $\mathrm{M}: 11.5+/-1.8$ & $\mathrm{M}: 7.2+/-1.2$ & $\mathrm{M}: 8.1+/-1.8$ \\
& $\mathrm{R}: 8-13$ & $\mathrm{R}: 5-13$ & $\mathrm{R}: 4-9$ & $\mathrm{R}: 4-12$ \\
\hline
\end{tabular}

"In each cross, the genotype of the female is given first, followed by the male.

In the $d a^{1 /}+\times 1(2) I I B 31 /+$ cross, $\sim 25 \%$ of the progeny show fewer PNS neurons than are observed in the normal range of variation within wild type $\left(+1+x+1+1\right.$; these were interpreted as being $d a^{1 / 1}(2) I I B 31$ in genotype. In these embryos, the peripheral neurons were counted in abdominal segments $1-6$. In the $d a^{1} /+\times 1(2) I I B 31 /+$ cross, the mothers were always da/ + in genotype. The number of neurons in each cluster was scored only for embryos showing PNS defects $(28 \%$ of the embryos; see Table 1$)$.

(M) Mean; (R) range; (n) number of abdominal segments scored.

form a continuous longitudinal tube (mean number of interruptions: $2.5 \pm 1.4$ ).

Epidermal primordium Because peripheral neurons and their associated sensory structures are derived from ectodermal cells, as are cells of the epidermis, we wanted to see whether their absence in mutant embryos was due to general defects of the epidermis. Cuticle preparations of mutant embryos reveal no external sensory structures but show the normal segmental pattern of ventral denticle bands (Fig. 4a) and the closely spaced noninnervated hairs on the dorsal surface (Fig. 4b). Thus, epidermal segmentation and the formation of the cuticular pattern between 15 and $18 \mathrm{hr}$ appear normal in mutant embryos. Because a number of external sensory structures are intermingled with the noninnervated dorsal hairs, the absence of external sensory structures without any accompanying holes or gaps in the field of
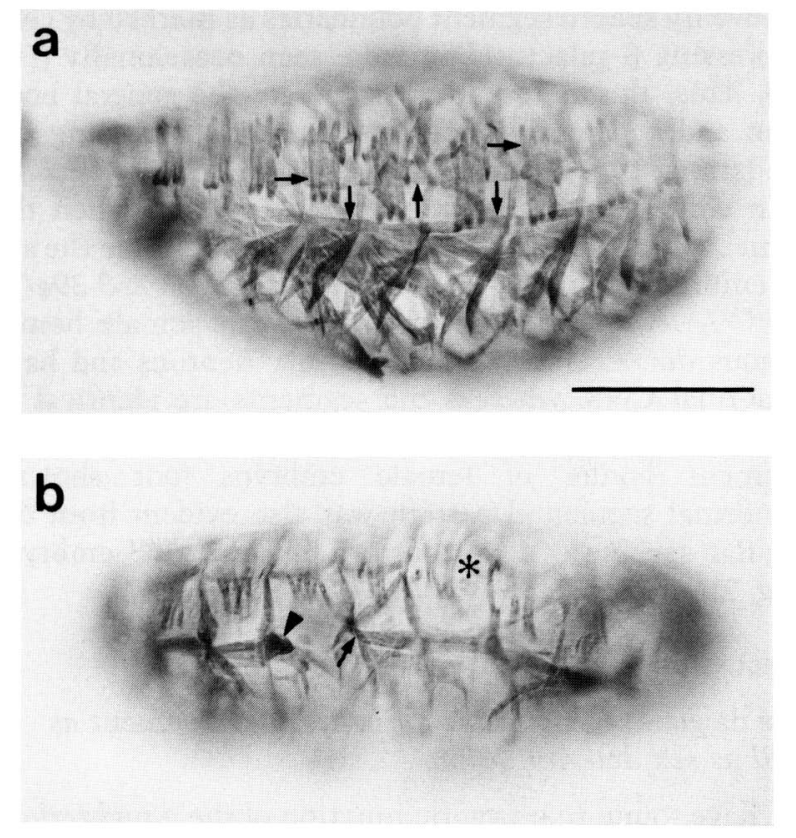

dorsal hairs indicates that the $d a^{I I 31}$ mutation specifically affects the formation of sensory neurons and associated sensory structures without generally disrupting the epidermis.

Although only results of the $d a^{I B 31}$ mutant analysis are shown, $d a^{2}$ and $d a^{3}$ mutants show very similar phenotypes. Gut and epidermis differentiate relatively normally. Muscle and tracheal defects do occur regularly but are moderate relative to the complete lack of peripheral neurons and external sensory structures. Moreover, the nonneural defects appear well after the neural defects have occurred. During the 8 - to 11 -hr period in which the PNS normally differentiates, the zygotic $d a$ mutant effects appear to be specific for the nervous system.

The embryonic phenotype due to loss of maternal $\mathrm{da}^{+}$ activity

To examine the strictly maternal $d a$ mutant effect, we crossed homozygous $d a^{1}$ females to wild-type males at $25^{\circ} \mathrm{C}$ and used the reciprocal cross as control (Table 3). Of embryos of $d a^{1}$ homozygous mothers, $50 \%$ show characteristic but variable defects. As will be described later, further experiments showed that the defective em-

Figure 3. Muscle formation in dalIB31 homozygous mutant embryos. (a) A 14-hr wild-type embryo labeled with the monoclonal antibody 6D5, which specifically labels muscle. Longitudinal muscles (vertical arrows) and circumferential muscles (horizontal arrows) occur in a segmentally repeated pattern. $|b|$ A 14-hr $d a^{I I B 31}$ embryo labeled with 6D5. The basic pattern of iongitudinal and circumferential muscles is present. However, longitudinal muscles are missing in at least one segment $\left({ }^{*}\right)$, and in another segment longitudinal muscles have broken away from one attachment site (small arrow) and are contracted to form a ball of labeled tissue (arrowhead) at the other attachment site. $d a^{I l B 31}$ homozygous mutant embryos are positively identified by their characteristic CNS defects. These defects are clearly visible in 6D5-labeled embryos when the CNS is labeled lightly with the neuron-specific antibody $44 \mathrm{C} 11$. Scale bar represents $100 \mu \mathrm{m}(a, b)$. 

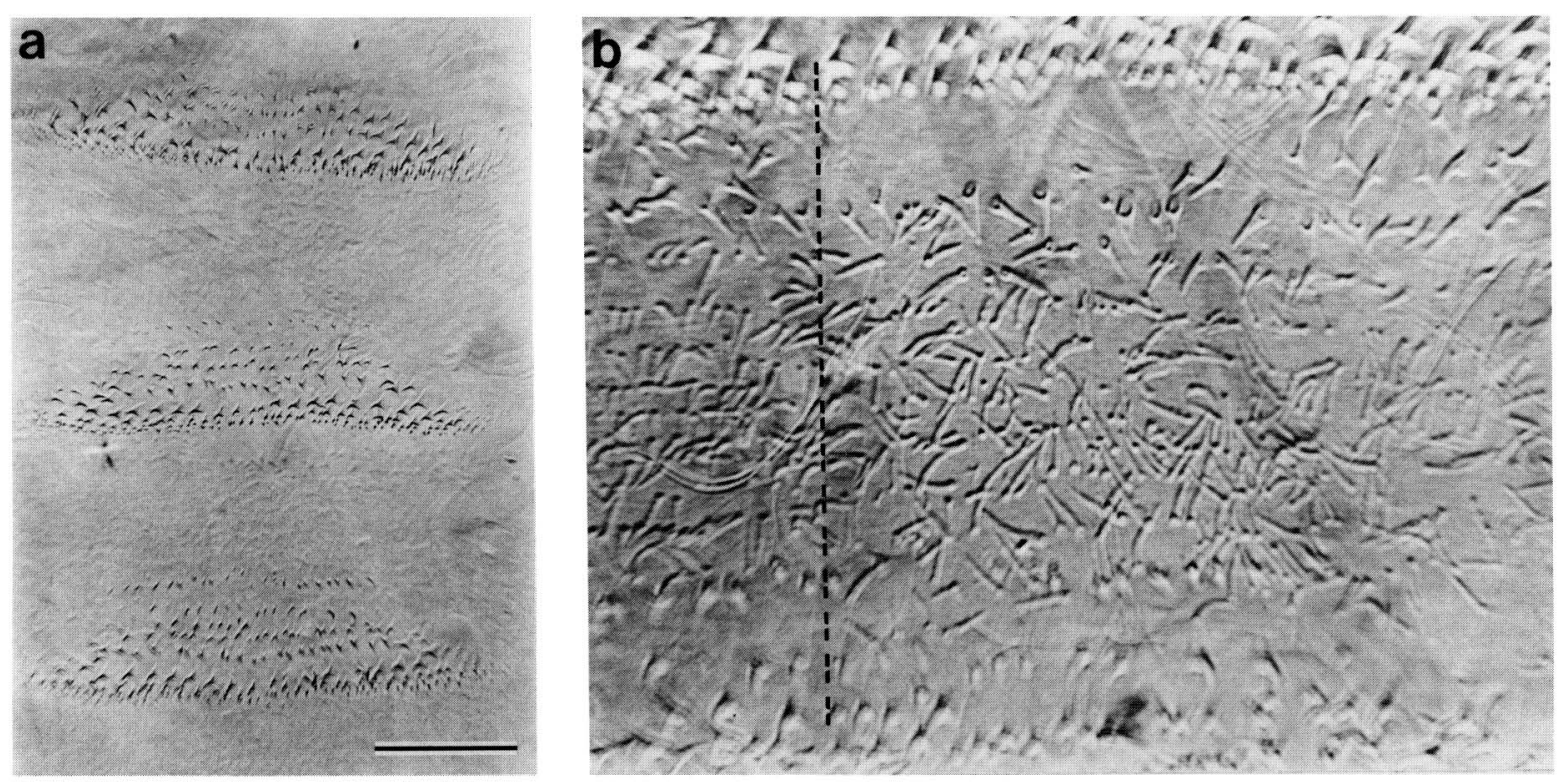

Figure 4. Epithelial segmentation and cuticle formation in $d a^{I I B 31}$ mutant embryos. $(a)$ Cuticle of a $d a^{I B B 31}$ mutant embryo. The morphology and pattern of the ventral denticle bands are normal (only three of the bands are shown). (b) The same mutant embryo cuticle preparation, showing fine, noninnervated hairs on the dorsal surface of one abdominal segment (the ventral denticle bands are visible, but out of focus, at the top and bottom of the figure). The vertical dotted line shows the approximate position of the dorsal midline. Fine, nonpigmented hairs cover the dorsal surface of abdominal segments in mutant embryos, as in wild type. Scale bar represents $50 \mu \mathrm{m}(a) ; 20 \mu \mathrm{m}(b)$.

bryos are all female progeny of $d a^{1} / d a^{1}$ mothers. The most consistent phenotypes are defects in the CNS: The CNS either shows reduced width in certain regions (Fig. 5a) or abrupt bends or twists (not shown). Sometimes an abnormally formed gut is found extended into the CNS (Fig. 5b). Unlike the zygotic phenotype of strong $d a$ alleles, embryos of homozygous $d a^{1}$ mothers do not show gaps in the CNS or discontinuities in trachea (Table 3). Defects in the muscles are also less frequent and generally milder than those of embryos homozygous for strong da alleles (not illustrated). Defects in either the number or placement of peripheral neurons were observed, but the degree of these defects varies widely. Some embryos show clear CNS defects but normal PNS, whereas in other cases, peripheral neurons are missing to a degree comparable to that observed in the $d a^{1} / d a^{I I B 31}$ embryos described earlier (Fig. 2).

The occurrence of these defects in about $50 \%$ of the progeny is consistent with the possibility that only female embryos are defective. To test this, we used a transformant line, $3-39 a$, that contains the $\beta$-galactosidase gene fused in frame with the transposase coding sequence of an X-linked P element (E. Bier, K. Lee, S. Shepard, and Y.N. Jan, unpubl.). This transformant shows $\beta$-galactosidase expression in the foregut and hindgut (Fig. 5b) and in rows of cells along the segment boundary (Fig. 5d). In crosses between males containing this $\mathrm{X}$ linked transposon and homozygous $d a^{1}$ females, all female and no male progeny are marked by this tissue-specific expression of $\beta$-galactosidase. In this case, we found that the maternal effect phenotypes described above are indeed limited to female progeny.

The expression of $\beta$-galactosidase in cells along the segmental borders of 3-39a transformants allowed us to examine the epidermis further. Irregularity in the size of segments had been suggested by the irregular spacing of peripheral neuron clusters (Fig. $5 \mathrm{c}$ ). This was confirmed in female embryos containing the X-linked transposon: Unevenly spaced segment boundaries as marked by cells expressing $\beta$-galactosidase were seen occasionally (Fig. $5 \mathrm{~d})$. This, the maternal effect affects the general body plan and apparently all types of tissues, including the epidermis.

In contrast to the maternal effect of $d a^{1}$, when the same $\mathrm{X}$-linked transposon was used to determine the sex of embryos from the cross $+/+$; $d a^{I I B 31 /}+\mathrm{X} \mathrm{3-39a/Y}$; $d a^{I B 31} /+$ we found that both male and female homozygous $d a^{I I B 31}$ embryos lack sensory neurons and have abnormal CNS, whereas the segments are identical in size, as judged by $\beta$-galactosidase expressing cells at the segment border of female embryos (not shown). A normal segmental pattern was also evident from the regular spacing of PNS clusters in $d a^{1} / d a^{I I B 31}$ embryos (Fig. 2).

\section{Discussion}

The da gene is important for neural development as well as sex determination

We have found that zygotic function of the daughterless 

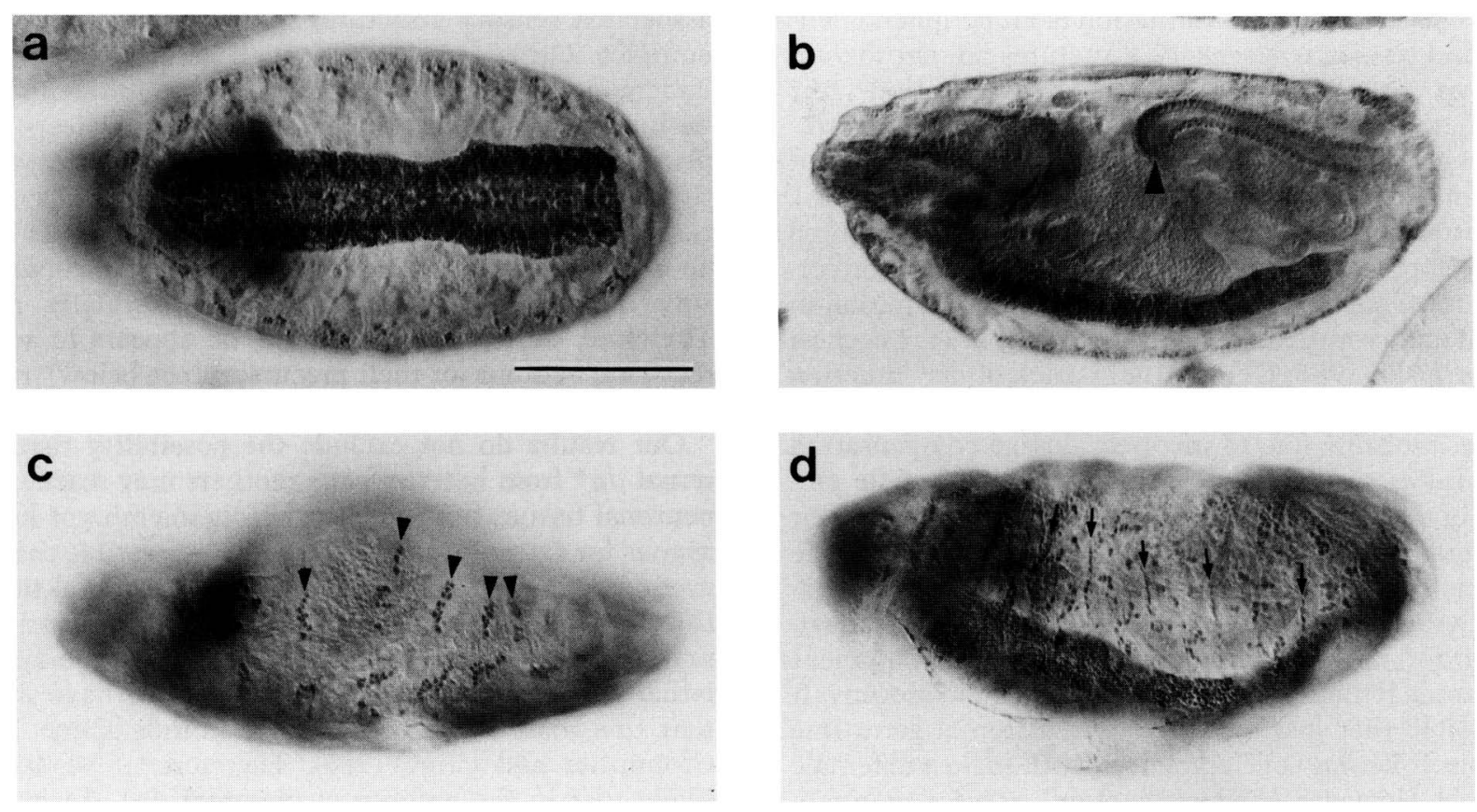

Figure 5. Defects in female embryos from $d a^{1} / d a^{1}$ mothers. (a) Ventral view of a 44C11-labeled 13-hr embryo from a cross between $d a^{1}$ homozygous females and wild-type males. The CNS is reduced in width midway along its length. $(b) 44 \mathrm{C} 11$ and anti- $\beta$-galactosidase labeling of a 13-hr embryo from a cross between $d a^{1}$ homozygous females and 3-39a transformant males. The X-linked $\beta$-galactosidase of 3-39a is expressed in the foregut and hindgut (large arrowhead) and serves as a marker for female embryos. The gut is malformed and has extended ventrally, causing a gouge in the CNS. (c) A 44C11-labeled 12-hr embryo from the same cross as in $a$. The dorsal clusters (arrowheads) of peripheral neurons are spaced irregularly, with widely varying distances between them. One cluster is displaced dorsally (upward) relative to the others. (d) Lateral view of a 13-hr 44C11 and anti- $\beta$-galactosidase-labeled female embryo from the same cross as in $b$. The expression of $\beta$-galactosidase in rows of cells along each segment boundary (arrows) reveals irregular spacing, indicating that the segments are unequal in size. Scale bar represents $100 \mu \mathrm{m}\langle a-d\rangle$.

Table 3. Maternal vs. zygotic da phenotypes

\begin{tabular}{|c|c|c|c|c|}
\hline Phenotype & $\frac{t}{t} \times \frac{t}{t}$ & $\frac{d a^{I I B 31}}{C y O} \times \frac{d a^{I I B 31}}{C y O}$ & $\frac{d a^{1}}{d a^{1}}(\mathrm{f}) \times \frac{+}{+}(\mathrm{m})$ & $\frac{+}{+}(\mathrm{f}) \times \frac{d a^{1}}{d a^{1}}(\mathrm{~m})$ \\
\hline Defective embryos $(\%)$ & $0(0 / 124)$ & $27(34 / 124)$ & $46(49 / 106)$ & $3(1 / 30)^{a}$ \\
\hline $\begin{array}{l}\text { PNS defects } \\
\text { mutant embryos }{ }^{\mathrm{b}} \text { with no PNS } \\
\text { percent of PNS missing in a } \\
\text { mutant embryo }\end{array}$ & $\begin{array}{l}-^{c} \\
-^{c}\end{array}$ & $\begin{array}{l}100(34 / 34) \\
100(34 / 34)\end{array}$ & $\begin{array}{c}0(0 / 49) \\
0-20 \text { (estimate) }\end{array}$ & - \\
\hline $\begin{array}{l}\text { CNS defects } \\
\text { Constrictions, twists, or kinks } \\
\text { Longitudinal gaps }\end{array}$ & $-^{c}$ & $\begin{array}{r}100(47 / 47) \\
85(44 / 52)\end{array}$ & $\begin{array}{c}100(46 / 46) \\
0(0 / 46)\end{array}$ & - \\
\hline $\begin{array}{l}\text { Tracheal defects } \\
\text { Interruptions }\end{array}$ & $0(0 / 24)$ & $90(27 / 30)$ & $0(0 / 22)$ & $0(0 / 30)$ \\
\hline
\end{tabular}

a This one defective embryo was abnormal in that its CNS was constricted in diameter along its length. NOTE: A $3 \%$ occurrence of abnormalities in wild-type populations is observed regularly.

b Homozygous $d a^{I I B 31}$ (i.e., zygotic effect) mutants identified by CNS defects. Maternal effect mutants identified by CNS, PNS, gut, and/or epithelial defects.

c Variations in scorable neurons are shown in Table 2. Otherwise, no CNS or PNS defects have been observed.

(f) Female; (m) male. 
gene is necessary for the formation of all peripheral neurons and associated sensory structures in Drosophila embryos. The PNS normally forms between 8 and $11 \mathrm{hr}$ after fertilization; thus, the neuronal phenotype correlates with the previously reported zygotic lethal phenotype and its temperature-sensitive period (Cline 1976). In contrast, the maternal function appears to be required at or prior to the blastoderm stage (Cline 1976) for correct dosage compensation and somatic differentiation in female embryos (Cline 1978, 1980, 1983, 1984; Lucchesi and Skripsky 1981; Gergen 1987). Lack of $\mathrm{da}^{+}$function in the maternal germ line results in female-specific lethality, probably due to incorrect dosage compensation (Cronmiller and Cline 1987). Because only female embryos of $d a^{1} / d a^{1}$ mothers are found to be defective, their abnormal development of the epidermis, as well as the nervous system, is most likely a consequence of the maternal effect of $d a^{1}$ on sex determination. In constrast, loss of $\mathrm{da}^{+}$zygotic function affects neural development and causes lethality in both male and female progeny. It is possible that loss of $d a^{+}$in the maternal germ line may affect neural development in both male and female embryos. However, a reduction of $d a^{+}$activity in homozygous $d a^{1}$ mothers has no detectable effect on their male progeny (Table 1). Similarly, the reduced $d a^{+}$activity in mothers heterozygous for $d a^{I I B 31}$ also caused no visible defects (Table 1). Thus, the da gene serves two important functions at different developmental stages: one concerns the determination of female somatic cells, and the other concerns the formation of sensory organs (Fig. 6).

\section{Neuronal specificity of the da zygotic phenotype}

The reduction of $d a^{+}$function in $d a^{1}$ homozygous mothers causes general disruption of apparently all types of tissues, including the nervous system. These defects are evident in female embryos but not in male embryos. In contrast, the loss of the zygotic $d a^{+}$function causes an early and complete removal of peripheral neurons and

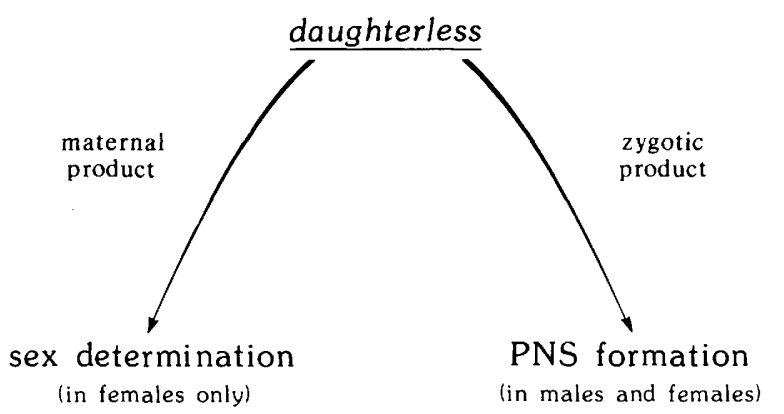

Figure 6. Contribution of maternal and zygotic $d a^{+}$product to sex determination and PNS formation. $\mathrm{da}^{+}$function in sex determination is primarily due to maternal product, whereas its function in neuronal development is primarily zygotic. This summary diagram is simplified and does not indicate all aspects of $d a^{+}$function. associated sensory structures in both male and female embryos. Other tissue types, such as gut, continue to undergo relatively normal morphological differentiation during the period in which the neuronal defects take place. Most significantly, the epidermis-from which the PNS and sensory structures are derived-also continues to differentiate normally for many hours after the neuronal defect has occurred, even in regions where sensory neurons and structures would normally form. Therefore, during embryogenesis, $d a$ appears to act directly on neurons (or their precursors; see below), rather than indirectly by disrupting the epidermis.

Our results do not exclude the possibility that maternal $d^{+}$from heterozygous mothers may rescue nonneuronal tissues from zygotic defects in embryos homozygous for extreme $d a$ alleles. If so, it is possible that the zygotic defects would be greater in nonneuronal tissues if there were less or no maternal $d a^{+}$. However, in assaying the maternal contribution of $\mathrm{da}^{+}$to the zygotic lethal phenotype, Cline and his co-workers have shown that this maternal contribution is minor (Cline 1976; Cronmiller and Cline 1986). Therefore, it seems unlikely that in the absence of maternal $d a^{+}$the zygotic phenotype would include gross defects in nonneuronal tissues.

Cronmiller and Cline (1987) have reported that mitotically induced clones of epidermal cells homozygous for either $d a^{2}$ or $d a^{3}$ are smaller and are observed less frequently in the adult than are wild-type control clones. From this, they concluded that $d a^{2}$ and $d a^{3}$ mutations block imaginal cell growth. In the embryo, however, the epidermis and the cuticular structures that are derived from epidermis late in embryogenesis are well formed (Fig. 4). Therefore, it appears that in the embryo these strong da mutations do not affect epidermal growth and differentiation but, rather, cause specific loss of all peripheral (and some central) neurons.

Muscles and trachea consistently show defects in strong da mutant embryos. In contrast to the PNS phenotype, the muscle and trachea phenotypes vary substantially among embryos: In some cases, the majority of muscles and trachea arise and differentiate in their normal positions, indicating that these nonneuronal tissues clearly can form even in strong $d a$ mutants. Furthermore, both muscles and trachea are innervated, and as these defects occur well after the neuronal defects take place, they may be due, at least in part, to lack of innervation or other indirect effects of the mutation. Consistent with this possiblility, we have observed similar (but generally less frequent) defects in muscle and trachea in embryos deficient for the achaete-scute locus which, like $d a$ mutant embryos, shows CNS defects as well as greatly reduced PNS (Dambly-Chaudiere and Ghysen 1987; Jimenez and Campos-Ortega 1987). Because the function and expression pattern of the AS-C appears to be specific for neurons and/or their precursors (Garcia-Bellido and Santamaria 1978; Cabrera et al. 1987; Romani et al. 1987), these observations also suggest that mutations of neuron-specific genes can affect muscles and trachea, possible by indirect means. 


\section{da function in neuronal development}

Having screened many chromosomal deletions and embryonic lethal mutations (Jan et al. 1987), covering $\sim 40 \%$ of the Drosophila genome, we have found only one gene, $d a$, that is required for the formation of all peripheral neurons and sensory structures. No peripheral neurons are present in strong $d a$ mutants when embryos of different stages are stained with various neuron-specific antibodies, including monoclonal antibody $44 \mathrm{Cl1}$; this antibody marks the first neuronal nuclei at about $7 \mathrm{hr}$ after fertilization, long before these neurons show any signs of morphological differentiation (Bier et al. 1988). No signs of monoclonal antibody 44C11-positive cells were detected in the periphery of $d a$ mutant embryos throughout development. Therefore, it appears that the $d a^{+}$zygotic function is necessary very early during peripheral neurogenesis. Early action of the $d a$ gene is also indicated by the simultaneous loss of neurons and their associated sensory structures: In cases where the lineage of insect peripheral neurons is known, the neurons derive from the same precursors as their support cells that form the sensory structures. Thus, da may function early, perhaps by blocking formation of the precursors of both peripheral neurons and their support cells. Furthermore, in a transformant line in which $\beta$-galactosidase is expressed in all peripheral neurons, their support cells, and probably their precursors, the strong da mutations eliminate all neural-related $\beta$-galactosidase expression (C. Dambly-Chaudiere, A. Ghysen, L.Y. Jan, and Y.N. Jan, in prep.|, again suggesting that the action of the $d a$ gene is likely to be early and necessary for the formation of all peripheral neurons and possibly their precursors. Together, these observations suggest that $\mathrm{da}^{+}$acts very early in peripheral neurogenesis and may be required for the ectodermal cells to become precursors of sensory neurons.

In both sex determination and neurogenesis, developmental control genes direct the choice of cells between alternative fates. The $d a$ gene appears to play an important role in an early step of both processes. In sex determination, da fuctions as a regulatory gene that is required for the sex-determination switch gene, $S x l$, to be properly expressed in female embryos (Maine et al. 1985). If $d a$ function in neurogenesis is analogous to its function in sex determination, it may be part of a regulatorys switch mechanism by which ectodermal cells take on the fate of neuronal precursors in the periphery.

\section{Experimental procedures}

Terminology

For clarity, we will use the designation $d a^{1}$ for the original hypomorphic allele, although the convention has been to omit the superscript 1.

\section{Stocks}

$d a^{1}, d a^{2}$, and $d a^{3}$ were obtained from T. Cline; $d a^{I l B 31}$ was originally isolated by Nusslein-Volhard et al. (1984). $D f(2 L) / 27$ was obtained from the Bowling Green stock center. The transfor- mant line 3-39a, with $X$-linked transposon containing $\beta$-galactosidase, was generated by $\mathrm{E}$. Bier and $\mathrm{K}$. Lee and will be described elsewhere. The original 1(2)IIB31 chromosome contained several other mutations that were removed by recombination and replaced with multiply marked chromosomal segments. $d a^{1}$ stocks were kept in uncrowded conditions at reduced temperature $\left(21^{\circ} \mathrm{C}\right)$. All other stocks were kept in uncrowded conditions at $25^{\circ} \mathrm{C}$. All crosses and embryo development were kept at $25^{\circ} \mathrm{C}$.

\section{Immunocytochemistry}

The antibody labeling and histological procedures have been described previously (Bodmer and Jan 1987). Use of the antiHRP antibodies (Jan and Jan 1982), and 21A4 antibodies (Jan et al. 1985) as neuron-specific markers has been reported earlier. The 44C11 antibody, which specifically labels neuronal nuclei in Drosophila, has also been described (Bier et al. 1988). The 6D5 antibody that specifically labels Drosophila muscles is a mouse IgG monoclonal antibody generated against Drosophila embryonic tissues.

\section{Cuticle preparations}

Procedures for making cuticle preparations of late embryos for the purpose of examining external sensory structures, as well as ventral denticle bands and noninnervated dorsal hairs, have also been described previously (Dambly-Chaudiere and Ghysen 1986).

\section{Acknowledgments}

We thank Sandra Barbel and Lisa Schulte for their generous assistance, and Drs. I. Herskowitz, P. O'Farrell, C. Kenyon, and H. Vaessin for critically reading the manuscript. We also thank Drs. C. Cronmiller and T. Cline for useful discussions and for allowing us to quote their unpublished studies on $d a^{I B 331}$, Dr. J. Tomkiel for communicating his results of noncomplementation between $d a^{1}$ and $d a^{I l B 31}$, Drs. J. Campos-Ortega and C. Nüsslein-Volhard for sending us the 1(2)IIB31 mutant stock and relating their observations of the mutant phenotype, and Dr. E. Bier for providing the 3-39a transformant. This study is supported by Howard Hughes Medical Institute and National Insititutes of Health (NIH) grant NS19191 to L.Y.J. and Y.N.J., and NIH postdoctoral fellowship to M.C., and Fonds National de la Researche Scientifique (FNRS) research grants to A.G. and C.D.-C.. A.G. is chercheur qualifie of the FNRS. Y.N.J. and L.Y.J. are Hughes Investigators.

\section{References}

Bate, C.M. 1978. Development of sensory systems in arthropods. In Handbook of sensory physiology, led. M. Jacobson) vol. IX, pp. 1-53. Springer-Verlag, New York.

Bell, A.E. 1954. A gene in Drosophila melanogaster that produces all male progeny. Genetics 39: 958-959.

Bier, E., L. Ackerman, S. Barbel, L. Jan, and Y.N. Jan. 1988. Identification and characterization of a neuron-specific nuclear antigen in Drosophila. Science (in press).

Bodmer, R. and Y.N. Jan. 1987. Morphological differentiation of the embryonic peripheral neurons in Drosophila. Wilhelm Roux's Arch. Dev. Biol. 196: 69-77.

Cabrera, C.V., A. Martinez-Arias, and M. Bate. 1987. The expression of three members of the achaete-scute gene com- 
plex correlates with neuroblast segregation in Drosophila. Cell 50: 425-433.

Campos-Ortega, J.A. 1985. Genetics of early neurogenesis in Drosophila melanogaster. Trends Neurosci. 8: 245-306.

Campos-Ortega, J.A. and V. Hartenstein. 1985. The embryonic development of Drosophila melanogaster. Springer-Verlag, New York.

Cline, T.W. 1976. A sex-specific, temperature-sensitive maternal effect of the daughterless mutation of Drosophila melanogaster. Genetics 84: 723-742.

- 1978. Two closely linked mutations in Drosophila melanogaster that are lethal to opposite sexes and interact with daughterless. Genetics 90: 683-698.

- 1980. Maternal and zygotic sex-specific gene interactions in Drosophila. Genetics 96: 903-926.

. 1983. The interaction between daughterless and Sexlethal in triploids: A lethal sex-transforming maternal effect linking sex determination and dosage compensation in Drosophila melanogaster. Dev. Biol. 95: 260-274.

. 1984. Autoregulatory functioning of a Drosophila gene product that establishes and maintains the sexually determined state. Genetics 107: 231-277.

- 1986. A female-specific lethal lesion in an X-linked postive regulator of the Drosophila sex determination gene, Sex-lethal. Genetics 113: 641-663.

Cronmiller, C. and T.W. Cline. 1986. The relationship of relative gene dose to the complex phenotype of the daughterless locus in Drosophila. Dev. Genet. 7: 205-221.

. 1987. The Drosophila sex determination gene daughterless has different functions in the germ line versus the soma. Cell 48: 479-487.

Dambly-Chaudiere, C. and A. Ghysen. 1986. The pattern of sense organs in Drosophila embryos and larvae. Wilhelm Roux's Arch. Dev. Biol. 195: 222-228.

- 1987. Independent subpatterns of sense organs require independent genes of the achaete-scute complex in Drosophila larvae. Genes Dev. 1: 297-306.

Garcia-Bellido, A. and P. Santamaria. 1978. Developmental analysis of the achaete-scute system of Drosophila melanogaster. Genetics 88: 469-486.

Gergen, J.P. 1987. Dosage compensation in Drosophila: Evidence that daughterless and Sex-lethal control X chromosome activity at the blastoderm stage of embryogenesis. $G e$ netics 117: 477-485.

Hartenstein, V. and J.A. Campos-Ortega. 1986. The peripheral nervous system of mutants of early neurogenesis in Drosophila melanogaster. Wilhelm Roux's Arch. Dev. Biol. 195: $210-221$.

Jan, L.Y. and Y.N. Jan. 1982. Antibodies to horseradish peroxidase as specific neuronal markers in Drosophila and grasshopper embryos. Proc. Natl. Acad. Sci. 72: 2700-2704.

Jan, Y.N., R. Bodmer, A. Ghysen, C. Dambly-Chaudiere, and L.Y. Jan. 1987. Mutations affecting the peripheral nervous system in Drosophila embryos. I. Cell. Biochem. Proceeding of the UCLA Symposium for Molecular Entomology, pp. 45-56.

Jan, Y.N., A. Ghysen, I. Christoph, S. Barbel, and L.Y. Jan. 1985. Formation of neuronal pathways in the imaginal discs of Drosophila melanogaster. J. Neurosci. 5: 2453-2464.

Jimenez, F. and J.A. Campos-Ortega. 1987. Genes in subdivision 1B of the Drosophila melanogaster X-chromosome and their influence on neural development. I. Neurogenet. 4: $179-200$.

Lawrence, P.A. 1966. Development and determination of hairs and bristles in the milkweed bug, Oncopeltus fasciatus (Lygaeidae, Hemiptera). I. Cell Sci. 1: 475-498.
Lucchesi, J.C. and T. Skripsky. 1981. The link between dosage compensation and sex differentiation in Drosophila melanogaster. Chromosoma 82: 217-227.

Maine, E.M., H.K. Salz, P. Schedl, and T.W. Cline. 1985. Sexlethal, a link between sex determination and sexual differentiation in Drosophila melanogaster. Cold Spring Harbor Symp. Quant. Biol. 50: 595-604.

Mange, A.P. and L. Sandler. 1973. A note on the maternal effect mutants daughterless and abnormal oocyte in Drosophila melanogaster. Genetics 73: 73-86.

Nüsslein-Volhard, C., E. Wieschaus, and H. Kluding. 1984. Mutations affecting the pattern of the larval cuticle in Drosophila melanogaster. I. Zygotic loci on the second chromosome. Wilhelm Roux's Arch. Devel. Biol. 193: 267-282.

Romani, S., S. Campuzano, and J. Modolell. 1987. The achaetescute complex is expressed in neurogenic regions of Drosophila embryos. EMBO I. 6: 2085-2092.

Sandler, L. 1972. On the genetic control of genes located in the sex chromosome heterochromatin of Drosophila melanogaster. Genetics 70: 271-277.

- 1977. Evidence for a set of closely linked autosomal genes that interact with sex chromosome heterochromatin in Drosophila melanogaster. Genetics 816: 567-582.

Wigglesworth, V.B. 1953. The origin of sensory neurons in an insect, Rhodnius prolixus (Hemiptera). Q. I. Microsc. Sci. 94: 93-112. 


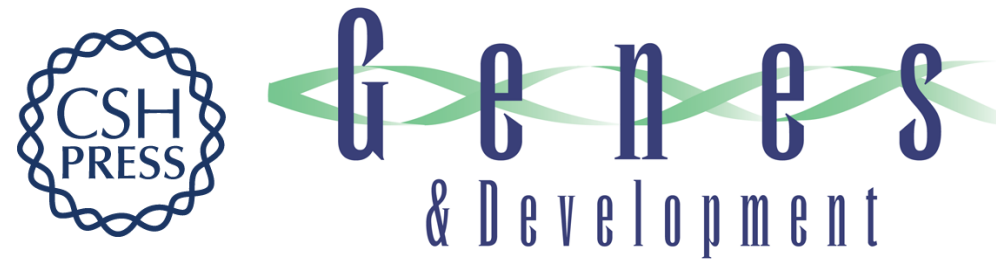

\section{The maternal sex determination gene daughterless has zygotic activity necessary for the formation of peripheral neurons in Drosophila.}

M Caudy, E H Grell, C Dambly-Chaudière, et al.

Genes Dev. 1988, 2:

Access the most recent version at doi:10.1101/gad.2.7.843

References This article cites 29 articles, 12 of which can be accessed free at: http://genesdev.cshlp.org/content/2/7/843.full.html\#ref-list-1

License

Email Alerting Service

Receive free email alerts when new articles cite this article - sign up in the box at the top right corner of the article or click here.

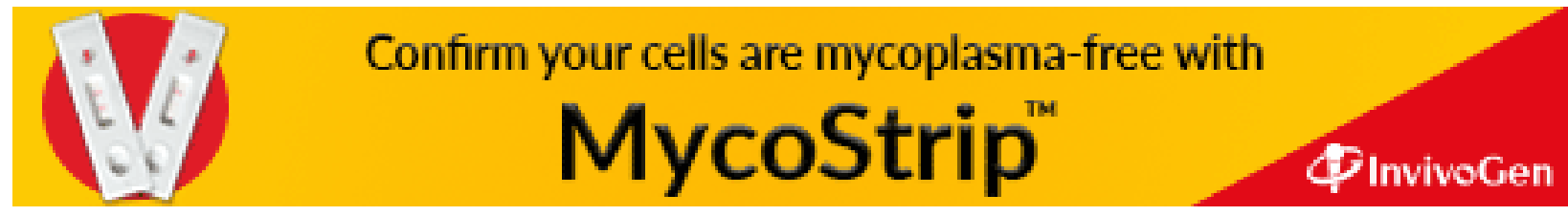

